\title{
Anesthetic Management of a Neonate with Subdural Hematoma
}

\author{
jili Basing ${ }^{1}$ Ashish Bindra² Niraj Kumar ${ }^{2}$ \\ ${ }^{1}$ Department of Anesthesiology, Pain Medicine, and Critical Care, \\ All India Institute of Medical Sciences New Delhi, India \\ ${ }^{2}$ Department of Neuroanaesthesiology and Critical Care, All India \\ Institute of Medical Sciences, New Delhi, India
}

J Neuroanaesthesiol Crit Care:2021;8:75-76

We report anesthetic management of a 7-day old, 3-kg male infant admitted to our hospital with complaints of poor feeding, lethargy (Glasgow coma scale [GCS] E1V1M5), and seizure. The baby was born via normal vaginal delivery and was apparently healthy at birth. There was no significant antenatal history or history of any drug intake during pregnancy. Noncontrast computed tomography (NCCT) of the head at admission revealed a large fronto-temporo-parietal subdural hematoma (SDH) in the left side, warranting urgent surgical intervention ( - Fig. 1). Preoperative international normalized ratio (INR) was 1.03 and the platelet count was $1,06,000 / \mathrm{mm}^{3}$.

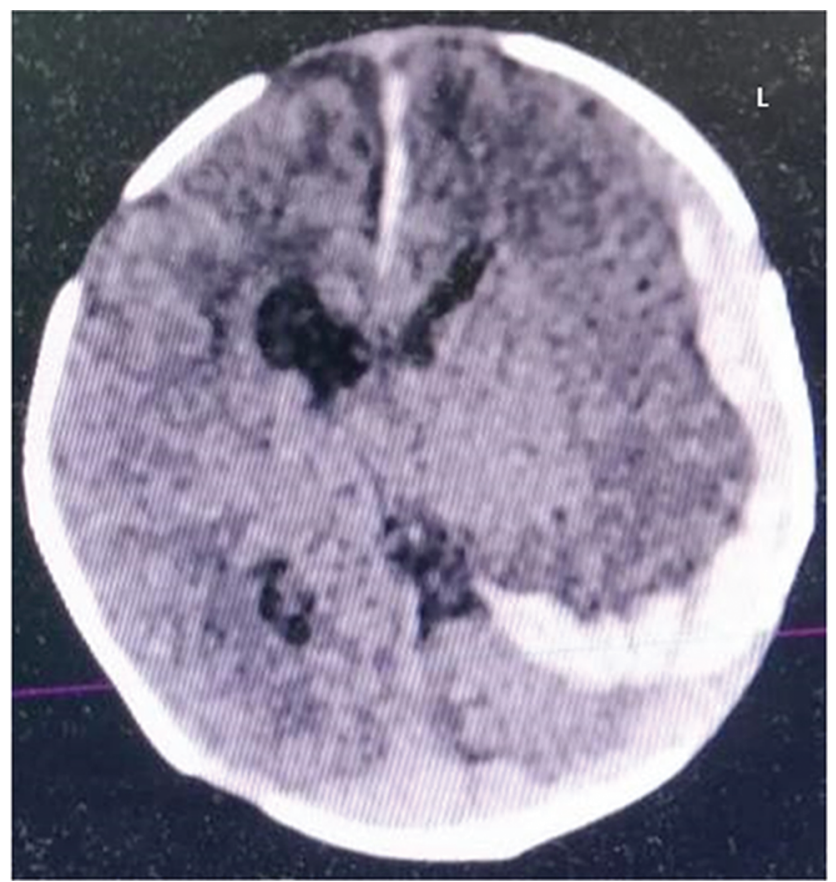

Fig. 1 Computed tomography scan showing fronto-temporo-parietal hematoma on the left side.
Address for correspondence Ashish Bindra, MD, DM, Room No. 710, Department of Neuroanaesthesiology and Critical Care, Neurosciences Centre, All India Institute of Medical Sciences, New Delhi 110029, India (e-mail: dr_ashi2208@yahoo.com).

In operating room, the patient was received with tracheal tube of 3.5-mm ID in situ and a respiratory rate of 30 breaths/min, heart rate (HR) of 150 beats/min, and blood pressure (BP) of $80 / 40 \mathrm{~mm} \mathrm{Hg}$. Anesthetic induction was done with fentanyl, oxygen, sevoflurane, and rocuronium. Right internal jugular vein and right femoral artery were cannulated for intravenous access and invasive BP monitoring, respectively. Intraoperative monitoring included 5-lead electrocardiogram (ECG), invasive BP, central venous pressure, pulse oximetry, temperature, urine output, and arterial blood gas (ABG) analysis. Fentanyl $1.5 \mu \mathrm{g} / \mathrm{h}$ and cisatracurium $0.3 \mathrm{mg} / \mathrm{h}$ with sevoflurane were used for maintenance of anesthesia. Normocarbia and normothermia were targeted. Intraoperative ABG analysis showed normal gas exchange with hemoglobin $(\mathrm{Hb})$ of $5 \mathrm{~g} / \mathrm{dL}$ and blood glucose of $158 \mathrm{mg} / \mathrm{dL}$. There were two episodes of intraoperative hypotension, which were managed with blood or fluid bolus and mephentermine $0.3 \mathrm{mg}$. A total of $180 \mathrm{~mL}$ of crystalloid was given intraoperatively. Blood loss was estimated to be $200 \mathrm{~mL}$ and was replaced with equal amount packed red blood cells (RBCs), platelets, and fresh frozen plasma (FFP) $(15 \mathrm{~mL} / \mathrm{kg})$. Toward the end of surgery (decompressive craniotomy), BP dropped again (40/28 mm $\mathrm{Hg}$ ) and an infusion of noradrenaline $1 \mu \mathrm{g} / \mathrm{min}$ was started. The patient was shifted to the intensive care unit (ICU) for elective ventilation with $\mathrm{HR} 160$ beats/min, BP $80 / 46 \mathrm{~mm} \mathrm{Hg}$, and temperature $35.2^{\circ} \mathrm{C}$ on noradrenaline infusion. Removal of SDH alone could not ensure adequate recovery due to complex multisystem effect of neurological injury. The patient was kept sedated and mechanically ventilated in postoperative period. Monitoring in ICU included 5-lead ECG, invasive $\mathrm{BP}$, central venous pressure, pulse oximetry, temperature, urine output, and $A B G$ analysis, along with monitoring of neurological status and postoperative hematological and biochemical investigations. The patient's BP dropped further, and dopamine infusion was started as well. Investigations
Published online August 26, 2020
DOI https://doi.org/

$10.1055 / \mathrm{s}-0039-1693500$

ISSN 2348-0548.
C2020. Indian Society of Neuroanaesthesiology and Critical Care. This is an open access article published by Thieme under the terms of the Creative Commons Attribution-NonDerivative-NonCommercial-License, permitting copying and reproduction so long as the original work is given appropriate credit. Contents may not be used for commercial purposes, or adapted, remixed, transformed or built upon. (https://creativecommons.org/licenses/by-nc-nd/4.0/).

Thieme Medical and Scientific Publishers Pvt. Ltd. A-12, 2nd Floor, Sector 2, Noida-201301 UP, India 
revealed coagulopathy with deranged prothrombin time, INR of 3, and platelet count of $62,000 / \mathrm{mm}^{3}$. Both platelets and FFP were transfused. Postoperative CT revealed removal of hematoma with evolving infarct. Despite all the steps taken to maintain hemodynamics and correct coagulopathy, the patient could not make it and succumbed to his injuries on first postoperative day.

Incidence of SDH in newborns is reported to be as high as $48 \%$; however, SDH requiring surgical decompression is rare. ${ }^{1}$ Causes include birth trauma or other traumatic injury, coagulopathy, or battered baby syndrome. Massive SDH due to birth trauma presents within 24 hours, but here the infant presented on day 7. Though the cause of SDH is not well known, it can also occur due to shaken baby syndrome. However, we could not directly elicit any such history. Trauma, dehydration, or presence of neonatal coagulopathy can cause massive SDH. Apart from trauma, systemic diseases may affect hemostasis, predisposing ill neonates to increased hemorrhagic or thrombotic events. The immature hemostasis system in preterm and very-low-birth-weight neonates can increase the risk of intraventricular hemorrhage. Due to emergency nature of surgery, we could not screen the neonate for coagulopathic disorders. Point-of-care testing such as rotational thromboelastometry or thromboelastrography may provide a clue to diagnosis and blood product replacement, but the results of such tests should be interpreted cautiously in neonates owing to immature coagulation system. ${ }^{2}$

Meticulous attention to fluid management, blood loss, temperature control, and analgesia is essential during neonatal neurosurgery. Surgery involving massive blood loss such as in our case results in replacement of entire blood volume and leads to hypothermia and coagulopathy, which may adversely affect the outcome apart from the injury itself. Appropriate anesthesia and analgesics are necessary even in neonates. We used volatile agent along with opioid to maintain anesthesia. Total intravenous anesthesia with propofol is better in tight brain, but there is a little evidence for its use in neonates. ${ }^{3}$ The use of propofol in neonates is off-label. The Food Drug and Administration (FDA) has approved it for maintenance of anesthesia only in children $\geq 2$ months of age and for induction of anesthesia in children $\geq 3$ years of age. ${ }^{4}$ Strict cutoff values regarding physiological parameters in neonates are limited. Hypotension and cerebral perfusion pressure limits in neonates are not very well defined., ${ }^{5,6}$ Though the new guidelines for management of severe pediatric traumatic brain injury (TBI) suggests a minimum cerebral perfusion pressure of $40 \mathrm{~mm} \mathrm{Hg}$, there may be age-specific thresholds with infants at the lower end and adolescents at or above the upper end of this range. ${ }^{7}$ Similarly, there are limited recommendations regarding choice of hyperosmolar therapy in neonates. ${ }^{8}$ Hypertonic saline is recommended for treatment of raised intracranial pressure in children with traumatic brain injury. Although mannitol is a widely used agent for this purpose, no studies meeting inclusion criteria were identified for use as evident from recent guidelines for pediatric TBI guidelines. Massive blood transfusion, tissue hypoxia due to hypotension, severe brain injury, and coagulopathy resulted in fatal outcome, but since only few neonates present for such emergencies, regular auditing and reporting are required to strengthen the evidence for management of such cases.

Massive SDH in a neonate for emergency neurosurgery is challenging, and it becomes more difficult when the cause is not certainly known. Strict vigilance and anticipation of complications, especially coagulation abnormalities in large SDH without any apparent history, should be kept in mind. Ruling out all probable causes of SDH, proper screening for neonatal coagulopathies, and prompt management are essential for favorable outcome.

\section{Conflict of Interest}

None declared.

\section{References}

1 Hong HS, Lee JY. Intracranial hemorrhage in term neonates. Childs Nerv Syst 2018;34(6):1135-1143

2 Revel-Vilk S. The conundrum of neonatal coagulopathy. Hematology (Am Soc Hematol Educ Program) 2012;2012:450-454

3 Shah PS, Shah VS. Propofol for procedural sedation/anaesthesia in neonates. Cochrane Database Syst Rev 2011;16(3):CD007248

4 Smith MC, Williamson J, Yaster M, Boyd GJ, Heitmiller ES. Off-label use of medications in children undergoing sedation and anesthesia. Anesth Analg 2012;115(5):1148-1154

5 Nafiu OO, Voepel-Lewis T, Morris M, et al. How do pediatric anesthesiologists define intraoperative hypotension? Paediatr Anaesth 2009;19(11):1048-1053

6 Allen BB, Chiu YL, Gerber LM, Ghajar J, Greenfield JP. Agespecific cerebral perfusion pressure thresholds and survival in children and adolescents with severe traumatic brain injury. Pediatr Crit Care Med 2014;15(1):62-70

7 Kochanek PM, Tasker RC, Carney N, et al. Guidelines for the Management of Pediatric Severe Traumatic Brain Injury, Third Edition: Update of the Brain Trauma Foundation Guidelines, Executive Summary. Pediatr Crit Care Med 2019;20:280-289

8 Upadhyay P, Tripathi VN, Singh RP, Sachan D. Role of hypertonic saline and mannitol in the management of raised intracranial pressure in children: a randomized comparative study. J Pediatr Neurosci 2010;5(1):18-21 